\title{
Maldescent of the testis
}

Maldescent of the testis occurs in as many as $4.3 \%$ male infants at birth $(2.7 \%$ for term and $21 \%$ for preterm infants). ${ }^{1}$ By the end of 6 weeks in the term infant and three months in the preterm, two thirds of these testes will have reached the scrotum. At one year of age the incidence of maldescent falls overall to $0.8 \%$. Half of these will be accounted for by the high scrotal testis. Failure of testicular descent is likely to be caused by either a disturbance of the hormonal environment (LH-RH $\rightarrow$ LH $\rightarrow$ testicular hormone axis), or mechanical factors obstructing the progress of testicular migration. Hormonal failure is responsible for the incompletely descended testis, while mechanical problems give rise to the ectopic testis.

It is of crucial importance to distinguish the retractile testis (a normal testis raised into the groin by the relatively powerful fibres of the cremaster muscle) from the maldescended testis. This is best achieved by careful clinical examination by an experienced practitioner. The child should be examined in the supine or squatting position, or both, in warm, comfortable conditions. The peak age incidence of retractile testis is 5-6 years. Thereafter, the incidence declines steadily until puberty when retraction of the testis out of the scrotum is uncommon. The ectopic testis refers to a testis which having emerged through the external ring takes an abnormal course. It is most commonly sited in the superficial inguinal pouch at the level of the pubic tubercle, but may come to lie in the perineal, femoral, superficial abdominal, or prepubic position. The incompletely descended testis is one which arrests along the normal pathway of descent. It is most frequently located within the inguinal canal or intraabdominally at the level of the internal inguinal ring. The testis is frequently small and atrophic, and is generally accompanied by a complete indirect inguinal hernial sac. If both testes are undescended, dysmorphic features should be sought as the testicular abnormality may be part of a syndrome (Aarskog syndrome, Smith-Lemli-Opitz syndrome, Prader-Willi syndrome, pseudo-Turner (male Turner) syndrome, or prune belly syndrome).

\section{Investigative procedures}

Patients with bilateral non-palpable testes should be given a course of human chorionic gonadotropin (HCG). A rise in plasma testosterone values is an indication of functioning testicular tissue. Precise localisation of a non-palpable testis may be achieved by a variety of non-invasive (ultrasonography, ${ }^{2}$ computerised tomography ${ }^{3}{ }^{4}$ ) or invasive (selective venography, ${ }^{56}$ laparoscopy ${ }^{7}$ ) investigations. Preoperative localisation of the testis may be helpful in determining the method and approach of orchidopexy.

\section{Orchidopexy and hormonal treatment}

The most valid indication for orchidopexy is the preservation of spermatogenesis. It has been clearly shown that the diameter of the seminiferous tubules and the number of spermatogonia decrease progressively after the second year of life. There is a concommitant increase in peritubular connective tissue leading to a widening of the interstitium. ${ }^{8}$ Ultrastructural changes on electron microscopy include a notable growth in the number of mitochondria and a loss of ribosomes in the endoplasmic reticulum, the spermatogonia, and the Sertoli cells. ${ }^{9}$ All these changes are absent during the first year of life but increase thereafter, depending on the duration of the malposition. The presence of a symptomatic inguinal hernia should lead to early surgical correction because of the appreciable risk of incarceration during the early months of life, with resultant vascular compromise to the ipsilateral testis. Other relative indications for orchidopexy include the increased risk of torsion or, rarely, trauma of the maldescended testis, and psychological factors. The risk of malignancy in maldescent is approximately 40 times that of a normally descended testis, ${ }^{10}$ which is an extremely rare condition (1:40 000 normal males). Although it has been speculated that early orchidopexy may provide some protection against malignant degeneration, ${ }^{11}$ placing the maldescended testis in the scrotum clearly facilitates early diagnosis of any subsequent malignant tumour.

Hormonal treatment as the definitive treatment, or as an adjunct to surgery for the maldescended testis, has been practiced for many years. The use of HCG or, more recently, luteinising hormone-releasing hormone (LH-RH) would theoretically be expected to be of some value in incompletely descended testis, as opposed to ectopic testis where mechanical factors prevent 'spontaneous' descent. Claims of up to $50 \%$ success have been reported by several investigators mainly from continental Europe. ${ }^{12}$ There is little doubt that some of the earlier series 
with high claims of success contained a large proportion of retractile testes. Hormonal treatment is less popular in the United Kingdom, where its use has been mainly restricted as a diagnostic test for bilateral non-palpable testes.

Orchidopexy should be undertaken around the age of two years if optimal spermatogenic function is to be attained. At this age the procedure may be performed on a 'day case' basis, whereas in the older child an overnight stay in hospital is advisable. The principles of the operative procedure consist of (1) mobilisation of the maldescended testis; (2) ligation and division of the associated inguinal hernia at the internal inguinal ring; (3) mobilisation of the testicular vessels as far proximally in the retroperitoneal region as necessary to be able to place the testis in the base of the scrotum without undue torsion; and (4) secure fixation of the testis in the scrotal sac to prevent subsequent retraction. The dartos pouch technique recommended in the early 1930 s by Petrivalsky ${ }^{13}$ is now practiced almost exclusively. It eliminates the need for external fixation and ensures secure anchoring of the testis in the scrotum without applying excessive traction on the testicular vessels. For the high undescended testis (intra-abdominal) various additional manoeuvres may be necessary. These include a two stage procedure $^{\mathbf{1 4}}$-division of the testicular vessels relying for vascularity on the vessels accompanying the vas deferens, ${ }^{15}$ and microvascular transfer of the testicular vessels to the inferior epigastric vessels. ${ }^{16} 1718$

\section{References}

1 Scorer CG. The descent of the testis. Arch Dis Child $1964 ; 39: 605-9$.

2 Madrazo BL, Klugo RC, Parks JA, DiLoreto R. Ultrasonographic demonstration of undescended testes. Radiology 1979;133:181-3.

3 Lee JKT, McClennan BL, Stanley RJ, Sagel SS. Utility of computed tomography in the localization of the undescended testis. Radiology 1980;135:121-5.

4 Wolverson MK, Jagannadharao D, Sundaram M, Riaz MA, Nalesnik WJ, Houttuin E. CT in localization of impalpable cryptorchid testis. $A J \boldsymbol{R}$ 1980;134:725-9.

5 Diamond AB, Meng C-H, Kodroff M, Goldman SM.
Testicular venography in the nonpalpable testis. $A J R$ 1977;129:71-5.

6 Glickman MG, Weiss RM, Itzchak Y. Testicular venography for undescended testes. $A J R$ 1977;129:67-70.

7 Scott JES. Laparoscopy as an aid in the diagnosis and management of the impalpable testis. J Pediatr Surg $1982 ; 17: 14-6$.

8 Mengel W, Wronecki K, Zimmermann FA. Comparison of the morphology of normal and cryptorchid testes. In: Fonkalsrud EW, Mengel W, eds. The undescended testis. Chicago/London: Year Book Med Publ, 1981: 57-94.

9 Hadziselimovic F, Herzog B, Seguchi H. Surgical correction of cryptorchidism at two years: electronic, microscopic and morphologic investigations. $J$ Pediatr Surg 1975;10:19-26.

10 Batata MA, Chu FCH, Hilaris BS, Whitmore WF, Golbey RB. Testicular cancer in cryptochids. Cancer $1982 ; 49: 1023-30$.

11 Whitaker RH. The undescended testis-the risk of malignant degeneration. Monogr Paediatr 1981 ;12:104-8.

12 Illig R, Torresani T, Bucher H, Zachmann M, Prader A. Effect of intranasal $\mathrm{LH} / \mathrm{RH}$ therapy on plasma $\mathrm{LH}$, FSH and testosterone, and relation to clinical results in prepubertal boys with cryptorchidism. Clin Endocrinol (Oxf) 1980;12:91-7.

13 Petrivalsky J. Zur Behandlung des Leistenhodens Zentralbl. Chirurg $1931 ; 58: 1001-5$.

14 Persky L, Albert DJ. Staged orchiopexy. Surg Gynecol Obstet $1971 ; 132: 43-5$.

15 Fowler R, Stephens FD. The role of testicular vasculature anatomy in the salvage of high undescended testes. In: Webster $\mathrm{R}$, ed. Congenital malformations of the rectum, anus and genito-urinary tracts. London: EJ Livingstone, 1963.

16 Kadowaki H, Yakami T. Basic study of microsurgical orchiopexy for high undescended testis; assessment of clinical applicability. J Pediatr Surg 1979;14:544-50.

17 MacMahon RA, O'Brien BMcC, Aberdeen J, Richardson W, Cussen LJ. Results of the use of autotransplantation of the intraabdominal testis using microsurgical vascular anastomosis. J Pediatr Surg 1980;15: 92-6.

18 Wacksman J, Dinner M, Straffon RA. Technique of testicular autotransplantation using a microvascular anastomosis. Surg Gynecol Obstet 1980;150:399-400.

LEWIS SPITZ

Department of Paediatric Surgery, Institute of Child Health, 30 Guilford Street, London WC1N 1EH 